\title{
8 \\ Social ethos and the dynamics of toleration
}

Jonathan Wolff

'The difficulty with toleration', writes Bernard Williams, 'is that it seems to be at once necessary and impossible. ${ }^{1}$ Toleration is necessary if groups with fundamentally different and conflicting values and beliefs are to live in peace together, but, so it is said, prima facie impossible under such circumstances. Why so? The idea of toleration only seems appropriate when a conflict of values or beliefs goes so deep that groups may think that 'they cannot accept the existence of each other'. Williams sums up: 'Toleration, we may say, is required only for the intolerable. That is its basic problem.'

Although Williams, unlike many others, refrains from calling this the 'paradox of toleration', there is something of a genuine puzzle here. As Williams indicates, formulating the apparent conditions under which toleration is required makes it rather difficult to see how those conditions could be satisfied. After all, it is not the case that all differences call for toleration. ${ }^{3}$ Under normal circumstances differences in hair colour do not call for toleration (although this is not to say that one cannot think of abnormal circumstances). Nor is it the case that all differences in beliefs, or values, call for toleration. Only differences of a certain kinds require toleration, so it seems; perhaps differences of a certain depth or fundamental nature. And it may be that when we spell out the nature of such differences the possibility of toleration may be remote.

The supposition that there is a puzzle or paradox here seems to presuppose what we could call the 'toleration presupposes repugnance' view. This is the view that the question of whether I should tolerate something only arises when I find myself revolted or otherwise offended by it. If I am untroubled, so it is said, toleration is not at issue.

It is not clear, though, that this is correct, at least in all cases. Is there anything wrong with the language of the person who says 'I'm a pretty tolerant sort of person: I don't find any beliefs or practices offensive or revolting'? Some will say that toleration lies between 'indifference' and 'empathy', and so this apparently super-tolerant person is not tolerant at all, but either indifferent or abundantly empathetic. Behind this verbal squabble, though, 
there is something of importance. There is no doubt that there is a normative element to toleration. It only makes sense to say that one tolerates beliefs or practices that fall into a certain class. Yet it is less clear that that class is 'the beliefs and practices I personally find revolting'. The alternative is to say that it is 'the beliefs and practices that often, or normally, are found revolting around here, or have been until recently (or if not here, then in places similar to this one)'. Thus, we can agree that overcoming, or somehow suspending, personal revulsion will often be part of the process of toleration; but it need not be. ${ }^{4}$ And, as has often been noted, when toleration of a practice becomes widespread enough - of interracial friendship, for example - describing this in terms of toleration normally loses its point.

It is probably important, though, to distinguish the issue of toleration as an individual virtue from that of the nature of a tolerant society, which is our central concern here. Yet there are bound to be some similarities (I will return to this later), and I think we have seen enough to be sympathetic to the idea that, in general, toleration requires an 'overcoming'. Thus, although it doesn't follow that we must see things this way, it makes sense to think of toleration as a particular process, and of a tolerant society as one that develops in a particular way. In other words, a tolerant society is one that has a certain dynamics. To bring this out it will be helpful to contrast it with another view. The view I question in its pure form - and whether anyone has ever explicitly held it is not at issue here - asserts that a tolerant society is the same thing as a politically liberal society, and that a politically liberal society is a society that is neutral between competing conceptions of the good. In sum, then, on this view, a tolerant society is a neutral society.

There is, no doubt, much to be said in favour of such a view, and it may well be that the alternative perspective I shall offer differs primarily only in emphasis. But note first that if we define a tolerant society in terms of whether or not it is neutral between certain competing conceptions of the good we seem to be looking at what we could call a structural feature of that society. We look at it not so much in its development but in its statics; what Nozick calls a 'current-time slice'. ${ }^{5}$ We take an inventory of laws and practices and examine them to see whether they are neutral or not.

What it means to pass this test will depend on the notion of neutrality at play. According to 'outcome neutrality' the essence of whether a society is tolerant depends on the consequences of its laws and practices for people's ability to live according to their own conceptions of the good. According to 'justification neutrality' the test will be whether or not assumptions about the relative superiority or inferiority of one conception of the good, or a range of conceptions, explicitly or implicitly enter into the justification of a society's laws and practices. ${ }^{6}$

Is there anything wrong with the claim that a tolerant society is a (justification-) neutral society? One obvious flaw is that we have never encoun- 
tered an entirely neutral society; indeed, on many views, no actual society has ever remotely come close. Yet we think we have encountered tolerant societies. Should we say, then, that social tolerance comes in degrees, and a society is tolerant to the degree that it is neutral? Perhaps, but let us look at a richer characterisation of a tolerant society; one that more centrally judges a society in terms of how it responds to change - in the dynamics of the system. An analogy from epistemology might help. Consider the question: how might we define a rational believer? One, apparently trivial, necessary condition of being rational is to have a set of consistent beliefs: the 'statics' of a rational believer. But this encounters one important problem: as a matter of fact, no one does. When the logical implications of everything a given person believes are fully spelt out, inconsistencies will be revealed. We have never encountered a truly consistent believer. Now we could try to define degrees of rationality, so that some inconsistencies of belief are still compatible with being rational to a high degree. However, a number of epistemologists have responded in a different way: by trying to define rationality at least in part in terms of the processes by which one updates one's beliefs in the light of new evidence. Thus, there are books called Knowledge in Flux, ${ }^{7}$ Change in View, ${ }^{8}$ and The Dynamics of Belief 9 (which was also the working title of Knowledge in Flux!).

There are, as with any analogy, limits to this one, which I introduce just to illustrate the possibility, and the possible advantages, of a shift of emphasis from statics to dynamics. My question is whether this shift might help us understand the nature of a tolerant society. The idea would be to say that a tolerant society should be understood not as neutral society but as a society that responds in certain ways to certain challenges. But challenges to what? And what are these challenges? And how should it respond? These are our questions.

\section{Social ethos}

If we are to take seriously the idea that a tolerant society is one with certain dynamics, then we need to come to an understanding of what it is that changes or, at least, is threatened with change. Here I want to appeal to the idea of a 'social ethos'. In general I want to say that everything that we would recognise as a society has a social ethos. This is not, however, intended as a definition of a society (as smaller groups too can have an ethos), but as one necessary condition. Some societies have a tolerant social ethos, and some do not, although this is going to be a matter of degree. But what, it will be said, is a social ethos?

It will be helpful, I think, to start with a model case, and then try to apply the lessons learnt there back to the case of an entire society. The case I want to consider is that of a big city firm of accountants, ${ }^{10}$ who pride themselves on the idea that 'here we work hard, but we play hard too', perhaps stating as much in their recruitment material on their website. This slogan, or prin- 
ciple, is likely to be exemplified in certain practices. The staff are likely to get to work early and stay late, and work through their lunch break. But on Friday nights they go out for drinks together, and at weekends they play team sports for the company against similar companies.

The 'work hard-play hard' slogan may seem at the core of the company's corporate ethos, but is itself expressive of some underlying values: profitability and collegiality, most likely. The company wants to make money, but it also, either for the same reason or independently out of goodwill, wants a workforce who get on with each other and identify with the company. So we can see here we have three levels to the company's ethos: first, fundamental values; second, slogans or principles; and third, practices. No doubt there are intermediate levels too, but for simplicity let us ignore them for now. My claim is that the corporate ethos is constituted by all three levels: each of values - which may only be implicit - principles and practices must all be in place for us to say that there is a genuine 'work hard-play hard' ethos. For consider another firm, which says exactly the same on its website, and the workers believe that they work hard and play hard, but in fact they don't: they get in late, do the easy crossword before starting work, and always get their regular trains home. Here we may say that there isn't so much an ethos in place as an ideology. Indeed, although there are no doubt many other uses of the term 'ideology', one important sense seems to be 'degenerate ethos'. An ideology, in this sense, is a deformed ethos where the principles and the practices do not match. (We might also consider whether an ethos could be deformed in other ways, but I will leave this to one side.)

When should we say that an individual shares the social ethos? One sufficient condition, presumably, would be when she values the values, believes and recites the principles, and follows the practices that exemplify the principles. Each of these, again, will be a matter of degree, and may allow us room to make a distinction between a strong and a weak social ethos. There are at least two dimensions by which a social ethos can be judged strong or weak. The first is that of those individuals who hold the ethos, how strongly they do so. With how much conviction do they recite the slogans, and how directly motivated are they to act on them? I say 'directly' motivated as a way of making Kant's distinction between acting from a principle and acting in accordance with it, perhaps out of the fear of the consequences of not doing so. Strength of an ethos is measured, in part, by action from the principle, governed by the values, rather than merely in accordance with it. ${ }^{11}$

The second dimension of strength is the proportion of the population of the society who adhere to the ethos. Thus it is obvious that an ethos can be strong according to one dimension and weak according to another. We might also add a third dimension of strength, which we could call pervasiveness. To explain, suppose we view a society as a complex set of relations, and suppose that an ethos is a set of norms to govern those relations: 
which relations should it govern? There are, for example, relations between citizens qua citizens; between citizens qua economic actors; between citizens and the state; between the state and individuals outside the state; between the state and other states, and so on, and so on. If a society that, say, in other ways values equality of opportunity nevertheless enforces fairly rigorous trade barriers we could say that this ethos is less pervasive than it might be. Whether we treat this as a third dimension of strength, or as an independent feature, may be a merely terminological question.

\section{The mechanics of toleration}

We introduced the idea of a social ethos as a way of pursuing the dynamic account of toleration: in effect the idea is that a tolerant society is one that has a social ethos that responds to challenges in a certain, tolerant, way. What I mean by a 'tolerant way' of responding will be clarified, but it is worth noting that 'tolerance' is, itself, sometimes, a mechanical, or at least an engineering, term. We talk about certain measurements having a degree of tolerance, meaning a margin of error, and to extend this use we could use the term 'tolerant' as the opposite of 'highly tuned'. A highly tuned engine, we might say, is one that responds badly to interference, or 'noise': it is intolerant, or unforgiving. This is exactly what so many people find so infuriating about computers. A more tolerant machine might still manage to do what it is meant to, even if the wrong key is pressed, or a little sand gets in the works. In other words, a tolerant machine is one that can fulfil its function even in the face of some dysfunctional elements. An intolerant machine, on the other hand, needs a sterile environment and operators wearing white gloves.

Should we say that a tolerant society is merely a society with a weak ethos; one that is held by few people, or by many people but only to a low degree? This, I think, is quite wrong. What is correct is that a tolerant society can have a weak ethos; and sometimes it can be tolerant because it has a weak ethos; but it seems to me just as likely that a society will be intolerant precisely because it has a weak ethos. That is because the ethos would crumble if it were not protected; it has to be protected from challenges through intolerance. This, indeed, may be how some totalitarian regimes have acted: because the ethos was so weak, no one is permitted to consider alternatives, for fear that alternatives would prove too attractive. If this is right, then tolerance is independent of strength.

So how should we model tolerance? Consider again the firm of accountants, happy in their 'work hard-play hard' ethos. Suppose, now, someone who does not share this ethos miraculously gets through the selection process. Suppose that this person subscribes to the 'family values' ethos. This means not routinely getting in early and routinely staying late, not socialising with workmates after hours or at weekends, but generally working efficiently enough that normal work tasks can be completed in 
normal working hours, in order to make room for a strong family life. How will the company respond?

Clearly there are several ways that the company may behave. It may well be said, for example, that this person is not a 'team player' and does nothing to contribute to an attractive working environment. Indeed, they may even be considered a disruptive influence by setting a bad example. If so, it may well be that they will be frozen out: perhaps they will not survive the probationary period. If such a decision is taken for this reason, we should say that this firm is extremely intolerant.

Of course they need not act this way. Another possibility is that, while strongly disapproving of the person's behaviour, they may decide not to dismiss them. This could be for various reasons: a feeling that to do so would be unfair - after all the person's work is adequate - or a feeling that this would draw a certain type of unwelcome attention on the firm. Rather than bring the issue to a head by firing this worker, perhaps they would adopt a different strategy: making the workplace discouraging enough to encourage them to leave of their own accord, but not doing anything to force the issue. This would mean passing them over for promotion, finding reasons why bonuses went to others, and so on. There must be many reallife examples of this. This is a form of toleration; but not the only form: if Marcuse hadn't taken the term for other uses we could call it repressive toleration; but here I shall call it 'grudging' tolerance. Toleration is adopted as a type of defensive strategy.

There is, though, another possible line of response. When confronted with the example of someone who works effectively, but to a different model, perhaps the senior management will take pause. It may be that they will reflect on the idea that there is more than one way of getting what they most want - profit - and feel that they should reconsider their principles and/or practices. After reflection they may start to review such things as their recruitment material, the type of activities they sponsor, and the general image they present. In other words they will treat the alternative working style on its merits, and come to appreciate and welcome it as a valuable alternative. To act this way is to be 'accommodatingly tolerant'. ${ }^{12}$

I said that we might define a tolerant society in terms of how it responds to certain challenges. We had three questions: what is it that is challenged; what are the challenges, and how does a tolerant society respond? We have seen answers in the accountants example: the ethos is constituted by the values, principles, and practices of the firm; it is challenged by someone who does not share the working principles, and it responds by recognising that there are other valid ways of working. Before trying to apply the lessons of this model back to the case of a whole society, it is worth bringing out the point that this model also shows something about the limits of toleration.

Recall that the model of an ethos involved a three-way distinction between values, principles and practices. At any time some collection of 
values, principles and practices constitutes the ethos of the group. We have examined the example of a person who joins the group but wishes to live by alternative principles. But why should we assume that all challenges appear at the level of principles? There could be challenges to practices and challenges to values too. Suppose someone comes up with the idea that everyone should get in an hour earlier in the morning for a group session in the gym, or that some other modification of sporting or social arrangements should take place. Again the three responses are possible: intolerance, grudging toleration or accommodating toleration. Facing such challenges is likely to put very little strain on the organisation, and the evaluation will simply be a question of whether this is a more effective way of putting the 'work hard-play hard' slogan into practice. Thus, the organisation needs to decide whether it will get more or less work out of its workers if they have the extra gym session, and whether encouraging this behaviour will improve morale or have the reverse effect.

At the other extreme consider another employee who, after gaining the confidence of the firm, proposes that the company should make many more charitable donations, and that it should seek out worthwhile organisations it can help at reduced or no fees, and who personally declines to work for clients whose activities he or she finds morally dubious, advocating very publicly that the company should drop these clients irrespective of the effect on profitability. This employee may, however, thoroughly approve of the 'work hard - play hard' part of the ethos. The conflict in this case is not at that level, but at the level of fundamental values. In this case the employee wishes to modify 'profitability' with 'social responsibility' at the level of core value.

Again the three responses are possible; however, in this case intolerance appears overwhelmingly likely to be the response. Grudging toleration is just about conceivable, provided a method of containment for this employee can be found, but accommodating tolerance seems unlikely in the extreme. It would be a complete rethinking of corporate goals, and why should the company do that? This is not to say that there cannot be large accountancy firms for whom social responsibility is important; but change is much more likely to be top-down than bottom-up.

Yet need it be that in order to be considered tolerant the firm has to change? A firm that gives serious consideration to the question of whether it should be more socially responsible - even if it ultimately rejects the proposal - is surely more tolerant than a firm that rejects the suggestion out of hand, other things being equal. Indeed, firms or organisations that make important changes without serious consideration would seem not to be so much tolerant as irresponsible. But what does it mean to give a challenge 'serious consideration'? In the case of challenges to practices or principles this is relatively easy to understand. Each is evaluated in terms of how it coheres with, develops or interprets some aspect at a more fundamental level within the ethos. So a proposed new practice may be evaluated by how 
well it exemplifies the principles, and a new principle by how well its implementation will realise the values. But how can we evaluate a challenge to the values? It seems that there is nothing more fundamental to which we can appeal, and if we take literally the idea that a value must be assessed on its own merits it will always win.

This is too quick, though. First, the idea of a three-level structure to an ethos is an over-simplification. In reality there are an indefinite number of levels and some values will be subordinate to others. Therefore, a similar structure of evaluating the less fundamental in terms of the more fundamental is possible. Second, we can evaluate values in the light of other values, even values at the same level. We can consider how well they mesh or cohere, or - a point of great importance - fall into an apparently natural pattern of change. Third, in some cases certain influences or pressures reflecting 'the spirit of the age' may be relevant. If a proposed new value is assessed in these, or other, ways, but is considered to be taking things 'too far', or in the wrong direction, it seems a bit hard to call the society that made this decision flatly intolerant. Perhaps we could introduce a category of 'reasoned intolerance'. This is a way of applying Mill's distinction between rejecting a view because it has been defeated after a full and fair hearing, and refusing to consider it altogether. However, although reasoned intolerance generally seems at least a step in the right direction, there may nevertheless be cases where this form and degree of calculation comes over as rather sinister, and may be found less excusable than mere bigotry. ${ }^{13}$ But clearly cases will differ.

\section{Back to society}

So much for the accountants. What, though, do we learn about the nature of a tolerant society as a result of this discussion? Earlier, I contrasted the view I favour with the view that, ultimately, a tolerant society is a neutral society. I suggested that a problem with this view is that we have never seen a fully neutral society. Yet, there is a more basic shortcoming with the neutralist view. The trouble is that we simply don't know how to be neutral until we know what we are meant to be neutral between. Neutralism requires us to be ready for anything, but who was prepared for the challenges Western societies have faced in recent times? We have discovered numerous ways in which our political and social institutions have turned out to be non-neutral in unexpected ways with respect to gender, race, sexual orientation, religion, disability and so on.

In reply it will be said that although we may have found our societies to be 'outcome non-neutral' it does not follow from this that they are 'justification non-neutral'. For this would be to say that the justification of its laws and/or practices depends implicitly or explicitly on assumptions about the relevant merits of different conceptions of the good. Clearly it is right that such a case needs to be made out more carefully, and cannot be inferred 
from the mere observation of non-neutral outcomes. But nevertheless, the claim still seems obviously true. For example, a great deal of recent and current law rests on assumptions about the 'ideal' family, and a certain amount of recent legal reform has been the consequence of the struggle to try to eliminate such assumptions in many areas of law. Thus, our societies are both outcome non-neutral and justification non-neutral. Yet we believe Western societies to be tolerant, and broadly I think we are correct.

But whatever we think about its desirability, I do not think that the goal of making societies justification-neutral is a reasonable one. We cannot predict what future challenges will be made to our unthinking assumptions. And even if we could, it will be both very difficult and very wasteful to make preparations to allow a place for new life styles or beliefs before we know whether any or many people will show much interest in living that way. The dynamic approach, by contrast, encourages us to react to what exists, including what has just come into being, rather than what is merely possible.

One good example of the dynamic approach is the way in which liberal societies are slowly adapting themselves to the existence of gay life styles. Although the nature of the challenge is different in different places, it seems fairly clear that a large proportion of people in Western societies were, and perhaps still are, revolted by the idea of homosexuality, and this had been encoded in various repressive laws. Toleration takes the form, first, of nonenforcement of law, and then repeal. Yet, as Mill and Marx both point out, the law can be tolerant without society being so, and discrimination continues to take many unofficial and indirect forms. Nevertheless, the situation is largely such that Western democracies have accepted the obligation of trying to work out ways in which gay people can be accommodated into society while overcoming or at least allaying the fears of those non-gays who, somehow, feel threatened. This may well be a case where society is more tolerant than the average of its people.

Now change is a long process, and is not complete. But this is something we should expect on the dynamic view. Because we have an existing ethos, and one that is not standing ready to plug in just any new life style or beliefs, whatever they are, change can take a long time. It is a way of working out how to fit different things together. This is, in part at least, an experimental question and can be solved in different ways in different places. Some moves may be seen to be counterproductive and unhelpful, and may be withdrawn. The lesson is that toleration can hardly mean instant acceptance.

How do these comments, though, relate to the 'accountancy' model? What insight does that model give us with this case, and others like it? I would prefer to approach this question from the other direction. Clearly, I would have not introduced it unless I thought it does a great deal to help illustrate the nature of social ethos; what it is for a social ethos to be strong or weak; and what it is for a social ethos to be tolerant or intolerant. But others may not be as charitable to my analogy as I am myself, and may 
argue that it fails to be illuminating. The main criticisms will centre on the claim that it is simply incorrect to say that contemporary liberal societies have an ethos in any way comparable to that of a firm of accountants, however large the firm, or small the society.

The most obvious difficulty, it will be noted, is at the level of fundamental values. If, as is sometimes said, liberal society does not attempt to advance fundamental values then, ultimately, the idea of new life styles presenting challenges does no work: there is nothing to challenge.

The equally obvious answer is that it simply isn't true that liberal society promotes no values in particular. This becomes particularly clear when we look at the theorists of liberalism. Early on in the Second Treatise, Locke makes the claim that human beings are naturally free, equal and independent. Other triads of rights or values are offered. Locke also gives us life, liberty and estate. We are also familiar with the calls for life, liberty, and the pursuit of happiness; and liberty, fraternity and equality. Rawls worries that leaning too hard on these, or similar, values would make liberalism 'but another sectarian doctrine', ${ }^{14}$ but it seems to me that Rawls (with his followers) are the exception to the tradition. As Rawls himself notes, by this standard the doctrines of Locke, Kant, Mill, and contemporary theorists such as Raz, are not properly forms of liberalism. Yet, however desirable one finds Rawls's position, it seems to me best to view it as a possible aspiration for society, rather than an account of existing liberal theory or practice. Liberal society does have some particular root values, although they tend to be rather vague and inclusive, and held 'implicitly'. ${ }^{15}$

Although it has played little explicit role in the philosophical tradition, the idea of 'the pursuit of happiness' may be central to our liberal ethos. Each individual has the right to pursue happiness ${ }^{16}$ in their own way, subject to constraints concerning harm to others, and, possibly, the use of resources. Conventional life styles embody folk wisdom about where happiness, and perhaps other values, are to be found. We might say, for example, that part of this conventional wisdom is the implicit principle that 'every man should have a wife, kids, and a job'. Now I cannot recall anyone actually saying this to me, but one can hardly doubt that it has determined many people's expectations for many generations.

Typically, conventional patterns of life or belief tend to become ossified and become treated as values in themselves, independently of the question of how well they realise the values to which they are instrumental. There is very good reason for this, for we generally do better by following traditions than by re-inventing the wheel. However, conventional patterns will not suit everyone equally well, and those who more easily find happiness in other ways may attempt life styles that we may at first find threatening. Why are they threatening? I don't find that this is an easy question to answer; but perhaps they are threatening because comparisons with difference require us to think and reflect upon our own lives and values, which is often an uncomfortable experience. 
The story so far, then, is this. Central to the liberal social ethos is the idea that each person has a right to pursue happiness. As a historical achievement we have found certain ways of living, in general, more conducive to happiness than others. These become conventional life styles, and the underlying assumption that these ways of living are preferable to others shapes many of our laws and practices. From time to time certain individuals find certain of these laws and practices overly constraining, and rebel by attempting to live in a way that allows them to pursue happiness in their own fashion, but does not coalesce with our existing laws and practices. This, then, provides a challenge to our social ethos.

Thus challenged, the model proposed suggests that we can respond in any of at least four ways: with intolerance (refusing to think); with grudging tolerance (acceptance as a way of avoiding the issues); with accommodating tolerance (coming to understand the value of the alternatives and making room for them); and with reasoned intolerance (being prepared to consider accommodation but finding that this is not possible without 'too much' revision). Accordingly, then, once we understand that existing liberal societies value the pursuit of happiness, we have a necessary core value with which to run our dynamic model of toleration.

It might be argued that if an ethos is to be adaptable in the way I suggest then it must have a special underlying value, perhaps 'live and let live'. If so, then this opens up two important challenges. First, the contrast between the dynamic and static disappears, for a society will be tolerant in virtue of one aspect of its social ethos. Second, the notion of 'live and let live' is so close to the idea of 'tolerate diversity' that the analysis becomes circular, presupposing the idea it is trying to explain.

Now the possible collapse of the distinction between statics and dynamics was always a threat. In brief, any disposition needs a 'categorical base' so ultimately the distinction between statics and dynamics is, as I have said, one of emphasis. But the problem of circularity is more troubling. However, my reply is that there is no single, special, value that all tolerant societies must endorse. A society might be tolerant, for example, purely because it is based on a strong doctrine of individual rights. Or it might be committed to the exercise of public reason. Or because its people are just naturally open-minded. The essence of toleration continues to depend on the process by which challenges are met, rather than any particular value or values underlying the process (even though some value or other must be present).

A different problem in applying the model, it will be said, is that the values of a liberal society are so thin and inclusive that there is no room for intolerance unless some sort of clear harm, to individuals or to public order, is threatened. But even if this is so, it is not an objection. A liberal society should hope, eventually, to be able to find room for all ways of life that do not damage third parties. But in addition this objection ignores the element of time-scale. Change may have to be slow. Thus, there may be rea- 
soned intolerance of particular practices, where the proposed rate of change is too much, too soon. We cannot expect the overturning of conventional wisdom to be swift.

Finally, I have claimed that a tolerant society is one that responds to certain challenges in particular ways; but what should we say about a society that, as a matter of fact, faces no challenges? Does it not make sense to ask whether or not such a society could be tolerant, nevertheless?

Here it is tempting to say that we need to consider certain counterfactuals: how would it respond in the face of challenges? However, the truth or falsity of such counter-factuals will depend on existing features of the society; i.e. its statics. In this respect, then, the contrast between the dynamic view and static view is again one of emphasis rather than deep philosophical difference. Nevertheless, it does seem, generally, to put the emphasis in the right place.

\section{Toleration as an individual virtue}

The dynamic analysis of toleration as a social virtue was initially motivated by the thought that toleration as an individual virtue typically requires some sort of 'overcoming'. Thus, the question arises of whether we should apply the dynamic model to individuals as well.

There is reason for disquiet here. The obvious way of developing the view is that an individual is tolerant only if she has a disposition to react in certain ways in the face of the experience of new life styles. Here, though, we meet the objection that someone could have, and espouse, extremely bigoted views, yet nevertheless has the right dispositions. It is simply that she has never faced the challenging circumstances, and so her tolerant dispositions remain unrealised. But on my analysis this bigoted person would be classed as tolerant. ${ }^{17}$

Now, of course, we will not discover that she is tolerant unless she faces a challenge, so her virtue may lie dormant. But this is not a problem. One can be musical without ever having played a note, for example, so we are generally prepared to recognise the existence of yet-unrealised dispositions. Rather the problem is, so it is claimed, that the bigot is not tolerant at all. So the analysis fails.

However, I think we need to press this further. Imagine a case of a person who expresses extremely bigoted views; perhaps virulently anti-gay. But, by hypothesis, he has never knowingly met a gay person, and so has never had a chance to put his bigotry into action in any concrete fashion. Now suppose a gay couple moves in next door. After his initial extreme unease our subject finds himself going out of his way to make them feel welcome, and to include the newcomers into the neighbourhood. His behaviour takes him, and others, by surprise. His bigoted remarks about gays in general may not have changed, but when it comes to a real challenge he behaves in a tolerant fashion. 
Now we need to ask, has this person suddenly become tolerant, or was he tolerant all along, 'underneath', without knowing it? Of course we now have evidence of tolerance, which we did not have before; but that it is not the question. It seems to me that we should say that he was always a tolerant person, but never had a serious chance to show it, or even find out for himself. So, just as there may be mute Miltons, there may also be bigoted tolerators.

\section{Notes}

I would especially like to thank Simon Evnine and Catriona McKinnon for extremely valuable written comments on a draft of this chapter. Versions of a paper on which this chapter is based were given at the University of Exeter, the University of Reading, the University of St Andrews, the University of Stirling, the University of Chicago at Illinois, and Columbia University. I would like to thank the audiences of those occasions for many difficult questions, and for not tolerating easy answers.

1 B. Williams, 'Toleration: An impossible virtue?', in D. Heyd (ed.), Toleration: An Elusive Virtue (Princeton NJ: Princeton University Press, 1996), p. 18.

2 Ibid., p. 18.

3 Indeed, it is not obvious that only differences call for toleration: for example 'she could not tolerate another child doing as well as her on the maths test'; 'she could not tolerate her secretary turning up at the party wearing the same dress'.

4 David Heyd's well-made point that toleration involves a shift of perspective from the evaluation of beliefs or values to an evaluation of the person holding them does, I think, provide an analysis of one type of toleration. It is less clear, though, that this is the only type of 'tolerance proper', even when tolerance is considered as an ethical, rather than a political, virtue, which is my focus here. See D. Heyd, 'Introduction', in Toleration: An Elusive Virtue, pp. 3-17.

5 R. Nozick, Anarchy, State, and Utopia (Oxford: Basil Blackwell, 1974).

6 See J. Raz, The Morality of Freedom (Oxford: Oxford University Press, 1986), pp. 110-62; and W. Kymlicka, 'Liberal individualism and liberal neutrality', Ethics, 99 (1989) 883-905.

7 P. Gärdenfors, Knowledge in Flux: Modelling the Dynamics of Epistemic States (Cambridge, MA: Massachusetts Institute of Technology Press, 1988).

8 G. Harman, Change in View: Principles of Reasoning (Cambridge, MA: Massachusetts Institute of Technology Press, 1986).

9 P. Forrest, The Dynamics of Belief: A Normative Logic (Oxford: Basil Blackwell, 1986).

10 Here I extend an example first used in J. Wolff, 'Fairness, respect, and the egalitarian ethos', Philosophy and Public Affairs, 27 (1998) 97-122.

11 It is interesting to note that when it is remarked that someone believes in certain values 'implicitly' this is often taken to indicate the strongest possible level of belief. This seems odd, for surely 'explicit' is generally stronger than 'implicit'. However, it makes perfect sense. If values are held implicitly they are not subject to the type of reflection and questioning that can cast doubt on explicitly held values. The strongest social ethos, therefore, may well be one where the values are held implicitly. This may also make it very hard for people to say what the 
ethos of their own society is. What, in detail, is the ethos of contemporary British society? This is a question to be asked, not of a British citizen, but, say, of a French sociologist long-resident in Britain (just as a native language speaker can rarely formulate the grammatical rules of their own language, without special training).

12 There may be other responses too; toleration for different types of reason. I do not mean to say that grudging toleration and accommodating toleration are the only possibilities. There may be further possibilities between the two.

13 I owe this point to Simon Evnine.

14 J. Rawls, 'Justice as fairness: Political not metaphysical', Philosophy and Public Affairs, 14 (1985) 223-51.

15 See Note 11.

16 Is 'happiness' the right word? It is becoming a philosophical commonplace that individuals may rationally and knowingly seek goals that make them unhappy. Yet, however well-established this point is in philosophical circles, it does not yet seem to have filtered down into folk wisdom.

17 I owe this observation to Catriona McKinnon. 